\title{
Effects of diclofenac sodium on rat hippocampus exposed to acute unilateral subdural hematoma: A histological, stereological and molecular study
}

\author{
Aysın Pınar Türkmen ${ }^{a^{*}}$, Suleyman Kaplana, Abdurrahman Aksoy ${ }^{\mathrm{b}}$, Berrin Zuhal Altunkaynak ${ }^{\mathrm{a}}$, Kübra Yurt ${ }^{\mathrm{a}}$, \\ Ebru Elibola $^{a}$ Cengiz Çoklukc, Mehmet Emin Onger ${ }^{a}$
}

${ }^{a}$ Department of Histology and Embryology, Faculty of Medicine, Ondokuz Mayls University, Samsun, Turkey

${ }^{b}$ Department of Pharmacology, Faculty of Veterinary Medicine, Ondokuz, Mayls University, Samsun, Turkey

${ }^{c}$ Department of Neurosurgery, Faculty of Medicine, Ondokuz Mayıs University, Samsun, Turkey

\section{ARTICLE INFO}

\section{* Correspondence to:}

Aysin Pınar Türkmen

Department of Histology and Embryology, Faculty of Medicine,

Ondokuz Mayıs University, Samsun, Turkey

e-mail: turkmenaysin@gmail.com

\section{Keywords:}

Acute subdural hematom

Biochemistry

Diclofenac sodium

Hippocampus

Stereology

\section{ABSTRACT}

In this study, it was aimed to evaluate the potential effects of acute subdural hematoma (ASDH) and diclofenac sodium therapy following ASDH on the rat hippocampus by histological, stereological and biochemical methods. For this aim, 24 male Sprague-dawley rats were used. The subjects were divided into 4 groups. One $\mathrm{ml}$ venous blood was collected from the tail vein of the all animals before seven day from experimental acute subdural hematoma. Plasma serotonin, adrenaline and noradrenaline levels were measured in these plasma samples. During experimental acute subdural hematoma: Non-heparinized $0.1 \mathrm{ml}$ of autologous blood from the tail vein of the animals in Group 3 and 4 were given to subdural space. Group 4 daily received intra-muscular diclofenac sodium administration at $15-\mathrm{mg} / \mathrm{kg}$-dose from the postoperative second hour to $7^{\text {th }}$ day of the operation. Group 1 and 2 used for control and sham operation, respectively. At postoperative $8^{\text {th }}$ day, $1 \mathrm{ml}$ venous blood from the all animals was collected before perfusion. The brain of animals were analysed by histological, stereological and biochemical techniques. The mean number of neurons in the CA1, CA2, CA3 regions of the hippocampus was estimated. Total number of neurons in the hippocampus of the diclofenac sodium treated group was significantly decreased. When comparing of postoperative blood samples, there was no difference between the levels of adrenaline and serotonin levels among the groups. But, only noradrenalin levels in the treated group it found to be higher than those of the sham and control groups $(\mathrm{p}<0.05)$. In this study, it was shown that using of diclofenac sodium after acute subdural hematoma caused to loss of the neurons in the hippocampal CA1, $\mathrm{CA} 2$, and CA3 regions.

J. Exp.Clin. Med., 2014; 31:139 